\title{
Estudio epidemiológico retrospectivo de las encefalitis equinas en tres departamentos de los Ilanos orientales
}

\author{
Retrospective epidemiological study of equine encephalitis in three \\ departments of the eastern plains
}

\section{Estudo epidemiológico retrospectivo da encefalite equina em três departamentos das planícies orientais}

\author{
Velásquez Prieto Sandra Milena ${ }^{1}$; Almansa Carrillo Yuli Marcela ${ }^{1}$; Hernández \\ Martínez María Cristina ${ }^{2}$ \\ ${ }^{1}$ Medico Veterinario y Zootecnista, Universidad de los Llanos \\ ${ }^{2}$ Medico Veterinario y Zootecnista MSc, Universidad de los Llanos
}

yuli.almansa@unillanos.edu.co

Recibido 18 de octubre de 2020. Aceptado 02 de junio 2021

\section{RESUMEN}

La Encefalitis Equina del Este (EEE) y la Encefalitis Equina Venezolana (EEV) son infecciones zoonóticas de importancia en salud pública, debido a que pueden causar encefalitis grave en équidos y humanos por picadura de mosquitos y por su alto potencial para traspasar fronteras; son causadas por virus de la familia Togaviridae, del género Alphavirus, de los que algunos ocasionan encefalitis en mamíferos y aves. Son enzoóticas en Venezuela y otras partes de América del Sur, siendo el virus de la EEV responsable de los principales brotes de enfermedades graves, a menudo mortales en animales y humanos. En Colombia existen zonas de mayor riesgo de presentación, teniendo en cuenta la circulación de los vectores trasmisores y condiciones geográficas que favorecen su proliferación, las cuales se encuentran ubicadas en altitudes menores de los $1200 \mathrm{msnm}$. El objetivo de este trabajo fue determinar el comportamiento epidemiológico de las encefalitis equinas basado en un estudio descriptivo-retrospectivo en dos departamentos de la región de la Orinoquia Colombiana, durante los años 2012-2018. Se utilizó la base de datos 
proporcionada por el Instituto Colombiano Agropecuario - ICA analizado mediante el método de Bortman por corredores endémicos. En el departamento del Casanare entre los años 2012 a 2018 se presentaron 62 focos de EEE, con el 91,9\% de los casos en el año 2016; con mayor frecuencia en los meses de julio, agosto y junio, en los municipios: Aguazul, Maní, Monterrey, Orocué, San Luis de Palenque, Tauramena, Trinidad y Yopal, sin focos en el año control 2019; de EEV se presentaron dos (2) focos en los años de 2012-2018; sin casos en el año control 2019. En el departamento del Meta, hubo ocho (8) focos de EEE, siendo los municipios de mayor incidencia: Puerto Rico, Cumaral y Guamal. Durante este período en los años de estudio, los meses con mayor incidencia fueron marzo, abril y junio. En el año control se presentó un brote epidémico durante los meses de febrero y marzo en el municipio de Puerto Rico, con un total de tres (3) focos reportados y 15 animales afectados. De EEV se presentaron dos (2) focos reportados en el año 2016, en los meses de enero y julio. El estudio sirve de ayuda para el control de las Encefalitis Equinas en el tiempo, siendo para la EEE los meses de mayor incidencia julio, agosto y septiembre probablemente por el aumento de la temperatura ambiental en estos meses y por ende por la multiplicación de los vectores; mientras que, para la EEV los meses de mayor incidencia fueron enero, febrero, abril y julio. El presente estudio arroja luces del comportamiento de estos y otros virus de importancia zoonótica en la región.

Palabras claves: Encefalitis equina, régimen lluvias, vectores.

\begin{abstract}
Eastern Equine Encephalitis (EEE) and Venezuelan Equine Encephalitis (EEV) are zoonotic infections of public health importance, because they can cause severe encephalitis in equids and humans due to mosquito bites and because of their high potential to cross borders; They are caused by viruses of the Togaviridae family, of the Alphavirus genus, some of which cause encephalitis in mammals and birds. They are enzootic in Venezuela and other parts of South America, with the VEE virus being responsible for major outbreaks of serious, often fatal disease in animals and
\end{abstract}


humans. In Colombia there are areas with a higher risk of presentation, taking into account the circulation of the transmitting vectors and geographical conditions that favor their proliferation, which are located at altitudes lower than 1200 meters above sea level. The objective of this work was to determine the epidemiological behavior of equine encephalitis based on a descriptive-retrospective study in two departments of the Colombian Orinoquia region, during the years 2012-2018. The database was provided by the Instituto Colombiano Agropecuario - ICA and was analyzed using the Bortman method by endemic corridors. Finding that in the department of Casanare between the years 2012 to 2018 there were 62 outbreaks of EEE, with $91.9 \%$ of the cases in 2016; more frequently in the months of July, August and June, in the municipalities: Aguazul, Maní, Monterrey, Orocué, San Luis de Palenque, Tauramena, Trinidad and Yopal, without outbreaks in the control year 2019; of VEE there were two (2) outbreaks in the years 2012-2018; no cases in the control year 2019. In the department of Meta, there were eight (8) foci of EEE, the municipalities with the highest incidence being: Puerto Rico, Cumaral and Guamal. During this period in the study years, the months with the highest incidence were March, April and June. In the control year, an epidemic outbreak occurred during the months of February and March in the municipality of Puerto Rico, with a total of three (3) reported foci and 15 affected animals. There were two (2) outbreaks of VEE reported in 2016, in the months of January and July. The study yielded data that help to control Equine Encephalitis over time, being for the EEE the months of highest incidence July, August and September, probably due to the increase in environmental temperature in these months and therefore by the multiplication of vectors; while, for VEE, the months with the highest incidence were January, February, April and July. Key words: Equine encephalitis, rainfall regime, vectors.

\section{RESUMO}

Encefalite Equina Oriental (EEE) e a Encefalite Equina Venezuelana (VEE) são infecções zoonóticas de importância para a saúde pública, pois podem causar encefalite grave em equídeos e humanos devido a picadas de mosquito e devido ao seu alto potencial de cruzar fronteiras; São causadas por vírus da família 
Togaviridae, do gênero Alphavirus, alguns dos quais causam encefalite em mamíferos e aves. Eles são enzoóticos na Venezuela e em outras partes da América do Sul, sendo o vírus VEE responsável por grandes surtos de doenças graves e muitas vezes fatais em animais e humanos. Na Colômbia existem áreas de maior risco de apresentação, levando em conta a circulação dos vetores transmissores e as condições geográficas que favorecem sua proliferação, que se localizam em altitudes inferiores a 1200 metros acima do nível do mar. O objetivo deste trabalho foi determinar o comportamento epidemiológico das encefalites equinas com base em um estudo descritivo-retrospectivo em dois departamentos da região colombiana de Orinoquia, durante os anos 2012-2018. Foi utilizado o banco de dados fornecido pelo Instituto Agropecuário Colombiano - ICA, analisado pelo método de Bortman por corredores endêmicos. No departamento de Casanare, entre 2012 e 2018, ocorreram 62 focos de EEE, com 91,9\% dos casos em 2016; com maior frequência nos meses de julho, agosto e junho, nos municípios: Aguazul, Maní, Monterrey, Orocué, San Luis de Palenque, Tauramena, Trinidad e Yopal, sem focos no ano de controle 2019; de VEE houve dois (2) surtos nos anos de 20122018; nenhum caso no ano de controle de 2019. No departamento de Meta, ocorreram oito (8) surtos de EEE, sendo os municípios com maior incidência: Porto Rico, Cumaral e Guamal. Nesse período nos anos do estudo, os meses de maior incidência foram março, abril e junho. No ano controle, ocorreu um surto epidêmico durante os meses de fevereiro e março no município de Porto Rico, com um total de três (3) surtos notificados e 15 animais afetados. Houve dois (2) surtos de EEV notificados em 2016, nos meses de janeiro e julho. O estudo auxilia no controle da Encefalite Equina ao longo do tempo, sendo a EEE os meses de maior incidência julho, agosto e setembro, provavelmente devido ao aumento da temperatura ambiental nesses meses e, portanto, à multiplicação de vetores. Enquanto para o VEE os meses de maior incidência foram janeiro, fevereiro, abril e julho. Este estudo esclarece o comportamento desses e de outros vírus de importância zoonótica na região.

Palavras-chave: Encefalite equina, regime de chuvas, vetores. 


\section{INTRODUCCIÓN}

La Organización Mundial de la Salud (OMS) con base en el reglamento sanitario internacional, señaló dentro de las amenazas para la salud pública mundial algunas enfermedades como la Encefalitis Equina Venezolana (EEV), Encefalitis Equina del Este (EEE), Encefalitis Equina del Oeste (EEO) y Encefalitis del Nilo Occidental (ENO) debido al alto potencial para traspasar fronteras; por tanto la vigilancia constante de casos probables, permite tomar medidas inmediatas para mitigar un brote de estas zoonosis, clasificadas por la Organización Mundial de Sanidad Animal (OIE) como enfermedades notificables por el impacto que producen en la salud pública y la economía mundial (INS, 2017; Guzmán-Terán, 2020).

La Encefalitis Equina Venezolana (EEV) y la Encefalitis Equina del Este (EEE), son zoonosis de importancia, por ser causadas por virus reemergentes, potencialmente mortales en équidos durante epizootias, que causan enfermedad neurológica en humanos contagiados (Forrester et al., 2017), con grave impacto social y pérdidas económicas en explotaciones pecuarias, siendo eventos de especial seguimiento en las Américas e históricamente circulantes en Colombia (Kumar et al., 2018).

Colombia tiene zonas geográficas características para la presentación de la EEV y la $E E E$, razón por la que la vigilancia epidemiológica requiere de un esfuerzo conjunto y coordinado entre las instituciones encargadas de la salud animal, salud humana y el medio ambiente, con la participación de gremios, comunidad y agencias de cooperación técnica internacional. El sistema de vigilancia debe coordinar actividades de recolección y análisis de información, que dispongan oportunamente en el tiempo y espacio de datos sobre la conducta de las encefalitis equinas y de los factores que condicionan su prevalencia (ICA, 2020a).

En Colombia se han detectado circulantes los virus de EEV y EEE; conocidos por su rápida propagación entre poblaciones de équidos, que actúan como amplificadores del virus transmitiéndolo a las poblaciones humanas (OPS, 2011). Anticuerpos del virus del Nilo Occidental, han sido reportado en equinos en los 
departamentos de Córdoba, Cesar y Sucre (Mattar et al., 2008).

La Organización Panamericana de la Salud (OPS) realiza recomendaciones para la prevención y control de enfermedades vectoriales como las encefalitis equinas, mediante programas integrales que incluyen planes de capacitación, divulgación y educación sanitaria, programas de vacunación, de atención oportuna de focos, diagnóstico oportuno por laboratorio, control de la movilización animal, sistemas de información y vigilancia epidemiológica, control de vectores y la vigilancia de huéspedes y reservorios, además de la participación comunitaria y la cooperación intersectorial en el ámbito nacional e internacional (Mesa et al., 2005).

Las encefalitis equinas se convierten en un importante reto para los servicios de salud humana, sanidad animal y producción pecuaria, debido a sus diferentes ciclos en la naturaleza e infección en diferentes hospederos, a las manifestaciones clínicas inespecíficas y variables que hacen compleja la definición de casos en humanos y animales y el establecimiento de acciones de promoción, prevención y control.

Según el Boletín "Colombia: Sanidad 2014" del ICA en 2017, la lluvia es un factor ambiental determinante en la multiplicación de la población de mosquitos, porque incrementa las posibilidades de infectarse con el virus y de transmitirlo a las especies susceptibles durante la época de sequía, ocasionando focos esporádicos. Por lo cual es fundamental conocer cuán endémicas son las encefalitis equinas, mediante la incidencia habitual en una región o en una época, así, la elaboración de los corredores endémicos, resulta una herramienta epidemiológica utilizada debido a la facilidad de su confección e interpretación, en la cual la incidencia actual puede ser representada gráficamente sobre la incidencia histórica y evaluar el comportamiento endémico o epidémico de las mismas; que una vez conocido, permita diseñar estrategias de prevención, control y toma de decisiones de forma temprana por parte de las instituciones encargadas de la vigilancia sanitaria en el país. 


\section{HISTORIA DE LAS ENCEFALITIS EQUINAS}

Desde el aislamiento del virus de la Encefalitis Equina Venezolana (VEEV) en el Estado Aragua (Venezuela) en 1938, se notificaron numerosos brotes, epidemias y epizootias en países de América, como: Colombia, Venezuela, Trinidad y Tobago, Costa Rica, México, Ecuador, El Salvador, Guatemala, Honduras, Nicaragua, Perú y Estados Unidos. Durante 1943 la epidemia se difundió por la costa de Venezuela hasta llegar a Trinidad (Tigertt et al., 1962).

Al mismo tiempo, la epizootia parece haberse extendido al sur y oeste, a lo largo de la costa del Pacífico de Colombia y llegó al Ecuador en 1941, donde continuó atacando a los equinos durante cinco años (Sotomayor, 1946; Kubes, 1944). Entre 1935 y 1961 hubo brotes en Colombia, Trinidad y Tobago, Venezuela y Perú (Ruíz, 1997).

En 1952 se aisló el VEEV en Colombia por primera vez en humanos bajo condiciones naturales en el municipio El Espinal (Tolima); entre 1955 y 1962 se realizaron aislamientos del virus Enzoótico en humanos con infección natural en San Vicente del Chucurí (Santander) en ausencia de epidemia; situación similar ocurrió en 1971, en Puerto Boyacá (Boyacá), indicando su carácter de foco endémico (INS, 2017).

En 1962 hubo un brote de Encefalitis Equina Venezolana (EEV) en la frontera colombo-venezolana que se diseminó más de 4.000 kilómetros llegando a países de Centro y Norte América (Vargas et al., 2009). La mayor epizootia y epidemia causada por la variante B del subtipo I del VEEV inició en Colombia en 1967 y se extendió a Ecuador, Venezuela, América Central, México y finalmente, alcanzó el Estado de Texas en Estados Unidos en 1971, falleciendo entre 38.000 a 50.000 équidos. En Ecuador se notificaron cerca de 31.000 casos en equinos y 310 muertes humanas y en Colombia, 200.000 casos (MS, 1995; Acha y Szyfres, 2003). 
En 1970 se notificaron brotes en seres humanos y animales de los estados venezolanos de Apure, Barinas, Cojedes, Guárico y Yaracuy. Se calcula que las muertes ocurridas en Apure ascendieron a 5.000 (Avilán, 1971).

Entre 1973 y 1992 hubo brotes esporádicos en Venezuela, Colombia y México. La última gran epidemia de EEV se presentó en 1995 asociada al subtipo IC, originada como consecuencia de un aumento de actividad viral en una población equina en áreas donde circulaba desde 1993, ocasionando 75.000 casos en humanos, con 0,4\% de fatalidad y 50.000 en equinos (Rivas et al., 1997, Colina y Blanchard, 2003).

Brotes en América del Sur y parte de Centro América confirman el papel continuo del virus como patógeno reemergente en humanos y equinos (Vargas et al., 2009). En Colombia se comprobó en 1958 la circulación del virus de Encefalitis Equina del Este en una población equina en San Vicente del Chucurí (Santander) en ausencia de epidemia. Situación similar ocurrió en Puerto Boyacá (Boyacá) en 1971 indicando su carácter de foco endémico (Mesa et al., 2005).

En noviembre de 2004, en una vigilancia serológica realizada en los departamentos de Córdoba, Cesar y Sucre, se encontraron en 12 equinos, anticuerpos al virus del Nilo Occidental, verificándose su circulación en Colombia (Berrocal et al., 2006).

En el año 2015, el Instituto Nacional de Salud (INS) confirmó por laboratorio cuatro casos de EEV en humanos, procedentes del municipio de Coromoro, (Santander) (Mesa et al., 2005). En 2016 se reportaron 22 focos de EEV en Magdalena, Cauca, Meta, Santander y Cesar (ICA, 2020a).

En el Casanare, entre junio y septiembre de 2016, se registró un incremento inusual de focos de EEE en équidos, pasando de uno a dos focos cada dos a tres años, a 55 focos en los municipios de Aguazul, Yopal, Tauramena, Maní, Orocué, Monterrey, Trinidad y San Luis de Palenque (INS, 2017).

\section{ENCEFALITIS EQUINA}

Las encefalitis equinas son infecciones zoonóticas de importancia en salud pública, debido a que pueden causar encefalitis grave en équidos y humanos por picadura 
de mosquitos y por su alto potencial para traspasar fronteras (INS, 2017); son causadas por virus de la familia Togaviridae, género Alphavirus, de los que algunos ocasionan encefalitis en mamíferos y aves (Pérez et al., 2019; CFSPH, 2008).

El género Alphavirus incluye ocho complejos genéticos/antigénicos, de los cuales cinco han sido descritos en el Nuevo Mundo (Weaver et al., 2012), dentro de este complejo están los que ocasionan la Encefalitis Equina Venezolana (EEV), Encefalitis Equina del Este (EEE), Encefalitis Equina del Oeste (EEO), el de Mayaro, de Mucambo y de Everglades (De la Hoz, 2000).

El virus de la EEV y el virus de EEE (Especie virus Madariaga en América del Sur) son enzoóticos en Venezuela y otras partes de América del Sur, siendo el VEEV responsable de los principales brotes de enfermedades graves, a menudo mortales en animales y humanos (principalmente subtipos BIA e IC) (Arrigo et al., 2010).

En Colombia existen zonas de mayor riesgo de presentación de las Encefalitis Equinas teniendo en cuenta la circulación del vector trasmisor y condiciones geográficas que favorecen su proliferación, las cuales se encuentran ubicadas en altitudes menores de los $1200 \mathrm{msnm}$ (ICA, 2013).

Las encefalitis equinas se convierten en un importante reto para los servicios de salud humana, sanidad animal y producción pecuaria, debido a sus diferentes ciclos en la naturaleza, infección en diferentes hospederos, manifestaciones clínicas inespecíficas y variables que hacen compleja la definición de casos tanto en humanos como en animales y el establecimiento de acciones de promoción, prevención y control (Mesa et al., 2005).

\section{ENCEFALITIS EQUINA VENEZOLANA (EEV)}

La EEV es la más importante de las encefalitis, por su severidad, alta morbilidad y letalidad en solípedos, es una enfermedad que emerge periódicamente en epizootias y epidemias combinadas. En América tropical, se caracteriza por su gran capacidad y velocidad para extenderse a otras áreas, como enfermedad infecciosa reemergente (Olano y González, 1997). 
Los virus del complejo EEV son clasificados en seis subtipos antigénicos (I a VI). El subtipo I, se divide en cinco variaciones antigénicas o serovares, $A B$ a $F$ (CFSPH, 2008); históricamente solo el subtipo I, variantes IAB y IC son capaces de producir epidemias/epizootias con mortalidad hasta del $85 \%$ en equinos (Weaver et al., 1996). Se dividen en grupos epizoóticos (Epidémicos) y enzoóticos (Endémicos). Los virus epizoóticos (IAB e IC) se amplifican en equinos y son responsables de la mayoría de las epidemias. Los virus restantes, incluyendo ID e IE y las variantes en los subtipos II-VI son subtipos enzoóticos (selváticos). (Walton y Grayson, 1989).

La variante ID es responsables de pequeños brotes en humanos en zonas rurales de Panamá, Colombia, Venezuela, Ecuador, Perú y Bolivia, mientras que la variante IE es responsable de brotes de la enfermedad en equinos en México, Belice y Guatemala. Los virus enzoóticos selváticos, se mantienen en bosques tropicales y subtropicales en el Norte, Centro y Sur de América transmitidos a roedores o aves acuáticas por mosquitos de las especies Culex melanoconium (Walton y Grayson, 1989).

Los virus enzoóticos alternan entre mosquitos del género Culex y marsupiales o roedores selváticos; las aves están involucradas en algunos ciclos, los humanos y los equinos son huéspedes incidentales. Se desconoce el reservorio natural de los subtipos epizoóticos entre epidemias. Los equinos son los principales amplificadores del virus de EEV epizoóticos durante las epidemias. Otros mamíferos no parecen ser epidemiológicamente significativos en la transmisión, sin embargo, en humanos se ha informado viremia suficiente para infectar mosquitos y en algunos casos bovinos y cerdos. Muchas especies de insectos hematógenos pueden transmitir el virus de EEV epizoótico, entre ellos los géneros Aedes, Anopheles, Culex, Mansonia, Psorophora y Ochlerotatus (CFSPH, 2008).

La enfermedad en equinos se caracteriza por fiebre, pérdida de apetito y trastornos del sistema nervioso central, como deterioro muscular, ceguera y convulsiones. En humanos, los primeros síntomas incluyen fiebre, escalofríos, malestar, mialgia en 
piernas y espalda baja, cefalea intensa, taquicardia y en algunos casos, náuseas, vómito y diarrea. Si hay signos neurológicos, incluyen convulsiones, somnolencia, confusión y fotofobia. En niños hay más probabilidad de sufrir daños neurológicos permanentes. Después de 4 a 6 días de enfermedad aguda, el paciente puede sentirse débil por varias semanas. Los casos letales se manifiestan con congestión difusa y edema en el cerebro, el tracto gastrointestinal y hemorragia pulmonar y, en ocasiones, desencadenan meningoencefalitis (Guzmán-Terán et al., 2020).

\section{ENCEFALITIS EQUINA DEL ESTE (EEE)}

Los virus de la EEE se clasifican antigénica y genéticamente en dos subtipos: el Norte Americano (NA) y el Sur Americano (SA) (Virus Madariaga), presentan diferencias biológicas importantes en su virulencia y ciclos de transmisión. El subtipo NA es genéticamente más homogéneo, patógeno para equinos y humanos, los virus del subtipo SA son genéticamente heterogéneos y menos virulentos para humanos (Monath y Tsai, 2002). Los virus del subtipo NA se transmiten en el Este de Canadá, Estados Unidos, México y El Caribe (Zacks y Paessler, 2010), la transmisión enzoótica y epizoótica del subtipo SA se ha descrito desde México hasta Argentina (OPS, 2011; Griffin, 2013).

Entre mayo y octubre, en Estados Unidos se notifican anualmente de 6 a 8 casos, principalmente en Florida, Georgia, Maryland, Wisconsin y Nueva Jersey. La tasa de letalidad es del $30 \%$ y se observan secuelas neurológicas en el $50 \%$ de los supervivientes (Banda y Debopam, 2020).

El virus Madariaga (MADV) anteriormente llamado virus de la EEE de Suramérica provocó su primer brote humano documentado en 2010 en Darién (Panamá), donde el VEEV, genéticamente similar, es endémico (Vittor et al., 2016). En encuestas serológicas en Panamá y la Amazonía peruana, de 2 a 5\% de población general tenía evidencia de infección previa por MADV, lo que sugiere que la infección humana leve o asintomática es relativamente común (Blohm et al., 2018). 
En el brote de 2010, se presentaron más de 100 casos sospechosos de encefalitis, de los que se confirmaron 13 casos de MADV, 11 de VEEV y uno de co-infección; 50 equinos fueron confirmados con MADV (Vittor et al., 2016). Antes del brote del Darién, en Sur América solo hubo tres casos notificados de VEEE en humanos en Brasil y Trinidad. En Norte América se informaron ocho casos entre 2004 y 2013 (Silva et al., 2017). Desde la perspectiva epidemiológica, las epidemias/epizootias de VEEV son explosivas e involucran la amplificación equina, con más de 100.000 casos en humanos y miles de muertes de equinos (Mattar y González, 2018).

\section{ESTRUCTURA DEL VIRUS DE LA ENCEFALITIS EQUINA}

El genoma viral está conformado por una cadena sencilla de ácido ribonucleico (ARN) de sentido positivo, de 65-75 nm, que consta de 11.700 nucleótidos y tiene características estructurales de ARN mensajero (extremo 5' con una caperuza metilada y una cola de poly-A en el extremo $3^{\prime}$ ), envuelto en una nucleocápside icosaédrica, conformada por múltiples copias de la proteína de la cápside. La cápside está rodeada por una envoltura lipídica, que deriva de la membrana plasmática de la célula hospedera, que ha sido previamente modificada por la inserción de dos glicoproteínas virales (Anthony y Brown, 1991; Greene et al., 2005).

La hemaglutinina es un componente inmunogénico en la superficie del virión y corresponde a las proyecciones de glicoproteína. El extremo 5 'del genoma codifica cuatro proteínas no estructurales: nsP1, nsP2, nsP3 y nsP4 y el extremo 3' es responsable de tres proteínas estructurales, la cápside y las proteínas de la envoltura E1 y E2. Las proteínas no estructurales participan en la replicación del genoma viral involucrado en funciones del citoplasma del hospedador (GuzmánTerán et al., 2020).

\section{EPIDEMIOLOGÍA}

En Colombia los virus que se han detectado circulando son el de EEV y el de EEE. Estos dos agentes son conocidos por la rápida propagación entre las poblaciones 
de caballos, burros y mulares que actúan como amplificadores del virus transmitiéndolo a las poblaciones humanas (Mattar et al., 2008).

En América tropical y subtropical se conocen varios focos naturales de EEV, donde las variantes antigénicas enzoóticas del virus circulan entre vertebrados inferiores y mosquitos. Los focos más reconocidos están ubicados en Belem (Brasil), Guajira, Magangué, Boyacá, Región de Urabá, Río Atrato, Tumaco y Santander (Colombia), Catatumbo, el estado de Miranda, La Guajira venezolana, Zulia (Venezuela), Sur de La Florida (EE. UU), Veracruz (México), Almirante, (Panamá), Paramaribo (Surinam), Bush (Trinidad y Tobago), así como en Argentina, Belice, Guatemala y Perú. También se ha comprobado la circulación del virus en la Amazonía peruana, así como en el Oeste de los Estados Unidos (virus Tonate, cepa Bijou Bridge) y es muy probable que existan otros focos naturales, aún no reconocidos en diferentes regiones tropicales y subtropicales de América (INS, 2017).

En 2008 se notificaron en Colombia, 89 predios con sospecha de Encefalitis Equina, de los cuales se diagnosticó EEV en un predio de Antioquia (ICA, 2008). En el 2009 se notificó en 65 predios; luego de ser colectadas las muestras, se descartaron 49 predios, se confirmó EEV en un predio de Mutatá (Antioquia). Los episodios clínicos notificados compatibles con la enfermedad se identificaron en 15 municipios; en este período se encontró una disminución del $27 \%$ en el número de notificaciones, con una similar dispersión geográfica que en el año 2008 (ICA, 2009).

Entre los Alphavirus de origen natural, VEEO, VEEE y VEEV tienen distribuciones generalizadas en América del Norte, Central y del Sur. EI VEEO se extiende a los EE. UU, desde el medio oeste (Michigan e Illinois) hasta la costa oeste y se extiende a Canadá con casos humanos reportados en 21 estados. EI VEEE se encuentra a lo largo del Golfo (Texas a Florida) y la Costa Atlántica (Georgia a New Hampshire), así como en el medio oeste (Wisconsin, Illinois y Michigan) y en Canadá, con casos humanos reportados en 19 estados. 
En contraste, la transmisión de VEEV ocurre predominantemente en Centro y Sudamérica. Al igual que con su distribución geográfica, los virus de la encefalitis equina se diferencian por sus principales especies de mosquitos vectores y su potencial zoonótico (Zacks y Paessler, 2010).

En 2010, se informó un brote por virus Madariaga (MADV) y virus de EEV en el este de Panamá, sugiriéndose que múltiples arbovirus están circulando en poblaciones humanas y equinas en Panamá (Carrera et al., 2018).

\section{TRANSMISIÓN DE LAS ENCEFALITIS EQUINAS}

Aunque el VEEE puede aislarse de más de 25 especies de mosquitos, el vector más importante en el ciclo enzoótico es el Culiseta melanura, que se alimenta principalmente de aves. Durante años, el VEEE se transmitió a los huéspedes mamíferos por medio de vectores puente, mosquitos que se alimentan tanto de aves como de mamíferos. Es posible que los caballos puedan amplificar el VEEE en los lugares donde se concentran las poblaciones de equinos y mosquitos. Durante brotes de la enfermedad en aves de caza, las infecciones son introducidas por mosquitos, pero propagadas en la bandada principalmente por el picoteo de plumas y el canibalismo. EI VEEO alterna entre gorriones y mosquitos culicinos, con una diversidad de mamíferos como huéspedes incidentales. Culex tarsalis parece ser el vector más importante; otros vectores significativos incluyen Aedes melanimon, Aedes dorsalis y Aedes campestris. (CFSPH, 2008).

Los caballos infectados con este virus no desarrollan una viremia significativa, y son los verdaderos huéspedes incidentales. No se ha informado la transmisión de persona a persona; sin embargo, se ha encontrado VEEV en Encefalomielitis equina: del este, del oeste y venezolana en secreciones faríngeas en humanos. Es estable cuando se aeroliza y, además, puede atravesar la placenta en mujeres embarazadas (CFSPH, 2008).

\section{IMPORTANCIA EN SALUD PÚBLICA}


La vigilancia en salud constituye una actividad de seguimiento, recolección sistemática, análisis e interpretación de datos sobre eventos de salud o condiciones relacionadas, cuya finalidad principal es alertar a las autoridades competentes con oportunidad suficiente para tomar medidas preventivas o de control. Esta vigilancia incluye el sistema de recolección de información que garantice la calidad del dato, la interpretación y los análisis adecuados para las autoridades sanitarias que deben enfrentar los problemas de salud. El sistema de vigilancia debe estar estructurado de manera que la magnitud o el tipo de problema no impidan la respuesta adecuada y para ello debe basarse en sólidas capacidades de diagnóstico y habilidad para la detección precoz desde el primer nivel de atención (Coutin et al., 2010).

Las Encefalitis Equinas aparecen en la lista del Código Zoosanitario Internacional de Epizootias de la OIE, razón por la cual, los países están comprometidos a mantener los sistemas de vigilancia e información, para declarar los casos detectados de estas enfermedades (SIVE, 1999). La EEV continúa siendo una amenaza constante para la salud pública y animal en el continente americano (Fabela, 2016).

Las encefalitis equinas son enfermedades importantes, debido al impacto negativo que ocasionan en lo económico y social y por sus graves repercusiones en la salud pública. El impacto social está representado por las repercusiones en la salud de las poblaciones rurales y urbanas localizadas en áreas endémicas y la pérdida de vidas humanas, lo que es capaz de generar colapso de los servicios de salud y efectos negativos en el bienestar comunitario. Las infecciones en humanos, que aparecen paralelamente a las de équidos, comienzan una a dos semanas después de los casos équidos. Sin embargo, a pesar de que los niveles de viremia van de moderados a altos, los humanos probablemente no contribuyan en forma significativa al mantenimiento de la onda epizoótica (Mesa et al., 2005).

En humanos, el período de incubación de la EEV puede variar de 1 a 5 días, la enfermedad tiene un comienzo súbito con escalofrío, dolor de cabeza, fiebre, dolor muscular y postración, leves movimientos de los ojos y rigidez de la nuca; la astenia, 
el mareo y el malestar general producen incapacitación del paciente. La temperatura es moderadamente alta acompañada de congestión conjuntival y enrojecimiento facial; pueden estar presentes faringitis, linfadenitis cervical y distensión abdominal. Los síntomas disminuyen en pocos días con desaparición de la fiebre, pero el dolor de cabeza y la debilidad persisten por varios días (Monath y Tsai, 2002; Azar et al., 2020) en algunos pacientes puede incluso provocar la muerte (Juárez et al., 2018).

Como resultado de la vacunación, en algunos países como los Estados Unidos, ya no hay epidemias periódicas graves de encefalitis por EEE y EEO; sin embargo, ocurren casos esporádicos y pequeños brotes. Aún continúa presentándose brotes epidémicos de EEV en América del Sur (Kumar et al., 2018; Carrera et al., 2018).

Para controlar la diseminación de los brotes de EEV durante las epizootias, se deben aplicar medidas cuarentenarias en las áreas afectadas, restringir la movilización y concentración de équidos desde y hacia una zona epizoótica y una no infectada, ya que la introducción de animales infectados en áreas libres crearía fácilmente nuevos focos de infección (Brito et al., 2003).

La vigilancia epidemiológica del VEEV comprende el monitoreo de la actividad vírica, las poblaciones de vectores, las infecciones en huéspedes vertebrados, los casos en seres humanos, el clima y otros factores, para poder detectar o predecir cambios en la dinámica de transmisión de los agentes víricos. Los programas de vigilancia deben centrar sus actividades en las zonas de mayor concentración de equinos, cercanas a los centros urbanos, o en los focos enzoóticos que ya han sido reportados previamente (Fabela, 2016).

\section{CANALES ENDÉMICOS}

La detección precoz del comportamiento anormal de enfermedades transmisibles depende de la calidad y oportunidad de la información disponible y de métodos eficientes (Coutin et al., 2010). 
La detección precoz depende de la calidad y oportunidad de la información, mientras que la determinación de si una enfermedad se encuentra en epidemia o no, requiere métodos sensibles y eficientes. La mayoría de los métodos empleados para evaluar desviaciones del comportamiento actual de un problema de salud versus su comportamiento esperado, se basan en el análisis de las series cronológicas que se conservan en las diferentes instancias del sistema de salud con las cuales se elaboran canales endémicos empleados para la vigilancia semanal o mensual de las enfermedades transmisibles (Coutin et al., 2000).

El canal endémico creado por Selwyn Collins en 1932 para la vigilancia de las epidemias de influenza y muy utilizado desde entonces debido a la simplicidad de su confección e interpretación, es una herramienta que permite conocer el comportamiento y evaluar la naturaleza endémica o epidémica de una enfermedad (IT Connect, 2020; CHM, 2020).

La elaboración de un corredor o canal endémico permite representar gráficamente la incidencia actual de una patología sobre la incidencia histórica de la misma, dando lugar a la detección temprana de cifras anormalmente altas o bajas, de los casos de la enfermedad en estudio. En las tareas de vigilancia epidemiológica en una población, es importante conocer cuán endémica es una enfermedad en dicha población o grupo de personas en un momento determinado del año (SME, 2013). Permite proveer información acerca del patrón de la propagación, tendencia en el tiempo y período de exposición e incubación de la enfermedad (SaluData, 2020).

Los métodos para confeccionar canales endémicos consisten en la obtención de una medida central que sirve como curva de expectativa y otras dos curvas que enmarcan el recorrido de fluctuación normal de la incidencia para cada uno de los intervalos de tiempo considerados, fundamentalmente semanas o meses, a partir de una serie notificada de casos. El aumento de la cantidad de años no mejora sustancialmente el análisis ya que es muy probable que se mantengan estables los factores que han generado la serie sobre todo los criterios diagnósticos, los 
mecanismos de notificación y registro y la endemia característica del evento (Bortman, 1999; Gómez, 2000; Marie et al., 2010).

El método más empleado y difundido para elaborar canales endémicos, utiliza el promedio de las medias geométricas de las tasas de incidencia de los últimos años. La ventaja de la media geométrica frente a la aritmética es que reduce la influencia que puede tener algún brote o epidemia que haya ocurrido en el período de estudio. Para construirlo se deben utilizar las tasas de incidencia y no el número de casos, aunque se trate de una población pequeña, a fin de evitar la influencia que puede tener cambios importantes en el tamaño de la población en el período tomado como referencia. En cuanto al número de años de la serie histórica, es aconsejable limitarlo a los últimos 5 a 7 , ya que un mayor número de años puede mejorar el modelo de predicción, pero las condiciones que mantienen la endemia verosímilmente pudieran haber variado en ese lapso, así como los mecanismos de notificación y registro (SERGA, 2020; OPS, 2011).

\section{METODOLOGÍA}

El trabajo de investigación se desarrolló en la ciudad de Villavicencio, con información sanitaria correspondiente a dos departamentos de los Llanos Orientales de Colombia, Meta y Casanare. Se realizó un estudio descriptivo, de tipo retrospectivo, empleando notificaciones del Instituto Colombiano Agropecuario (ICA) para Encefalitis Equina Venezolana (EEV) y Encefalitis Equina del Este (EEE) en dos departamentos de los Llanos Orientales: Meta y Casanare. Con la base de datos suministrada por el ICA se construyó una plantilla de cálculo de Excel de Microsoft ${ }^{\circledR}$ 2013, con el reporte anual del ICA regional Meta de las notificaciones de Encefalitis Equina Venezolana y Encefalitis Equina del Este, en los departamentos del Meta y Casanare, desde el año 2012 hasta el 2019, complementando la información con los boletines sanitarios mensuales, semestrales y anuales del ICA en su página web. 
La información se organizó cronológicamente por meses y luego por año, para totalizar las notificaciones y estimar la tasa de las enfermedades por año, se estableció el promedio de población equina afectada y el inventario equino por departamento, así como el número de predios inscritos por año en la región. Se caracterizó el comportamiento epidemiológico de los focos de EEV y EEE reportados por el ICA en los departamentos del Meta y Casanare.

Para la elaboración de los canales endémicos se utilizó la metodología propuesta por Bortman (1999), tomando como dato de entrada el número de notificaciones de focos EEV y EEE por mes y por año. Se empleó para el manejo de los datos, el método de la media geométrica de las tasas y sus intervalos de confianza.

En una hoja electrónica de Excel se situaron los meses en las filas y en las columnas, los años, con base en la frecuencia de la EEV y EEE en un período de siete años, entre 2012 y 2018. En otra columna, se calculó la media geométrica de los siete años por mes. Para calcular la media geométrica $(\mu)$, se realizó una transformación logarítmica de los valores mediante la fórmula.

$$
\mu=\log x
$$

Donde $x$ es el valor inicial y $\mu$, el valor transformado, de los cuales se obtuvo los cálculos posteriores (Medias, desviaciones estándar e intervalos de confianza), los datos obtenidos se convirtieron en unidades originales, calculando el antilogaritmo. Para la gráfica del canal endémico, se tuvo en cuenta: La zona de éxito, por debajo de la curva inferior; la zona de seguridad, entre la curva inferior y la media; la zona de alerta, entre la curva media y la superior, y la zona de epidemia, por encima de la curva superior (Bortman, 1999).

El procesamiento de datos y la elaboración de figuras se realizaron en Excel de Microsoft ${ }^{\circledR}$ 2013. La base de datos se analizó estadísticamente empleando el software SPSS versión 23. 
De la información consolidada se obtiene el cálculo de la media geométrica de las tasas y las desviaciones estándar de los valores de cada mes, se elabora el canal endémico para la Encefalitis Equina Venezolana y la Encefalitis Equina del Este.

\section{RESULTADOS Y DISCUSIÓN}

El Instituto Colombiano Agropecuario - ICA seccional Meta, consolidó en una base de datos, el historial de los focos de Encefalitis Equina Venezolana (EEV) y Encefalitis Equina del Este (EEE) para los departamentos del Meta y Casanare, entre los años 2012 y 2018, tomando el 2019, como año control, con la cual se construyeron los canales endémicos de la EEV y EEE para los departamentos del Meta y Casanare.

La presentación de Encefalitis Equina del Este en el departamento del Casanare entre el período de 2012 a 2018, totalizó 62 focos, distribuidos en aproximadamente 7.133 predios. En los años 2014, 2015, 2016 y 2018 se presentaron focos de EEE, con el $87,1 \%$ de estos en el 2016. La mayor frecuencia se dio en los meses de Julio con un total de 22 focos, seguido de agosto con 20, junio con siete (7) y septiembre con seis (6) focos. Según los boletines sanitarios anuales reportados por el ICA, los municipios con mayor incidencia de EEE fueron: Aguazul, Maní, Nunchía, Monterrey, Orocué, San Luis de Palenque, Tauramena, Trinidad y Yopal, municipios cercanos geográficamente.

Según los boletines mensuales del ICA, en el año 2014, el departamento del Casanare presentó focos de EEE en tres municipios, San Luis de Palenque y Nunchía pertenecientes a la Unidad Territorial Norte y el municipio de Maní de la subregión Centro. En San Luis Palenque se presentó EEE en el mes de abril afectando un total de 27 equinos, de los cuales fallecieron dos (2). En Maní el foco se presentó en el mes de julio con seis (6) equinos afectados y un deceso de éstos; mientras que, en Nunchía el foco se reportó en el mes de septiembre con cuatro (4) equinos positivos, de los cuales uno (1) murió. 
De acuerdo con los boletines sanitarios semanales del ICA, se presentó en el 2015, un foco de EEE en el municipio de Orocué en la semana epidemiológica 28, correspondiente al mes de junio. Para el año 2016, se reportaron en el Casanare focos de EEE en la subregión Norte en los municipios de San Luis de Palenque, Orocué y Trinidad, en la subregión Centro en los municipios de Aguazul, Maní y Yopal y en la subregión Sur en los municipios de Monterrey y Tauramena.

En los municipios con reporte de focos de EEE en el año 2016, se vieron afectados un total de 871 equinos, distribuidos en ocho (8) municipios, siendo Yopal el de mayor presentación con el $57,9 \%$ de los animales positivos, seguido de Aguazul con 186 y Trinidad con 92. De igual forma, Yopal reportó 22 equinos fallecidos con el $61,1 \%$ del total, seguido de Aguazul con 11 (Tabla 1).

Tabla 1. Letalidad y frecuencia de equinos afectados y fallecidos por EEE. Casanare. 2016

\begin{tabular}{|c|c|c|c|c|}
\hline \multicolumn{2}{|c|}{ Municipio } & $\begin{array}{l}\text { Equinos } \\
\text { afectados }\end{array}$ & $\begin{array}{l}\text { Equinos } \\
\text { fallecidos }\end{array}$ & $\begin{array}{l}\text { Porcentaje } \\
\text { de letalidad }\end{array}$ \\
\hline Aguazul & & 186 & 11 & 5,9 \\
\hline Maní & & 22 & 0 & 0,0 \\
\hline Monterrey & & 17 & 0 & 0,0 \\
\hline Orocué & & 11 & 0 & 0,0 \\
\hline San Luis & de & 12 & 1 & 8,3 \\
\hline Palenque & & & & \\
\hline Tauramena & & 26 & 1 & 3,8 \\
\hline Trinidad & & 92 & 1 & 1,1 \\
\hline Yopal & & 505 & 22 & 4,4 \\
\hline Total & & 871 & 36 & 4,1 \\
\hline
\end{tabular}

En noviembre de 2018 se reportó un foco en Villanueva con cuatro (4) equinos afectados y cero decesos. Con base en estos datos se obtienen estadísticamente por el método de Bortman, las tasas de incidencia por año, calculando la media geométrica y los límites superior e inferior para los focos de los siete (7) años de estudio. Dando como resultado un límite superior de cuatro (4) focos para los meses 
de julio y agosto, dos focos para los meses junio y septiembre y tan solo uno (1) para abril, octubre y noviembre. Los demás meses no presentaron focos.

El corredor endémico de la EEE en el departamento del Casanare tuvo una tendencia ascendente a partir del mes de marzo hasta llegar a un pico bajo en el mes de abril, con un leve descenso en el mes de mayo y un pronunciado ascenso en el mes de julio, para descender nuevamente en los meses subsiguientes, con una estabilización en los focos del mes de octubre y noviembre, con declive en el mes de diciembre. El año control (2019) estuvo dentro de la zona de éxito, al no presentarse ningún foco en este período (Gráfica 1).

Gráfica 1. Canal endémico de EEE. Casanare, 2012-2018

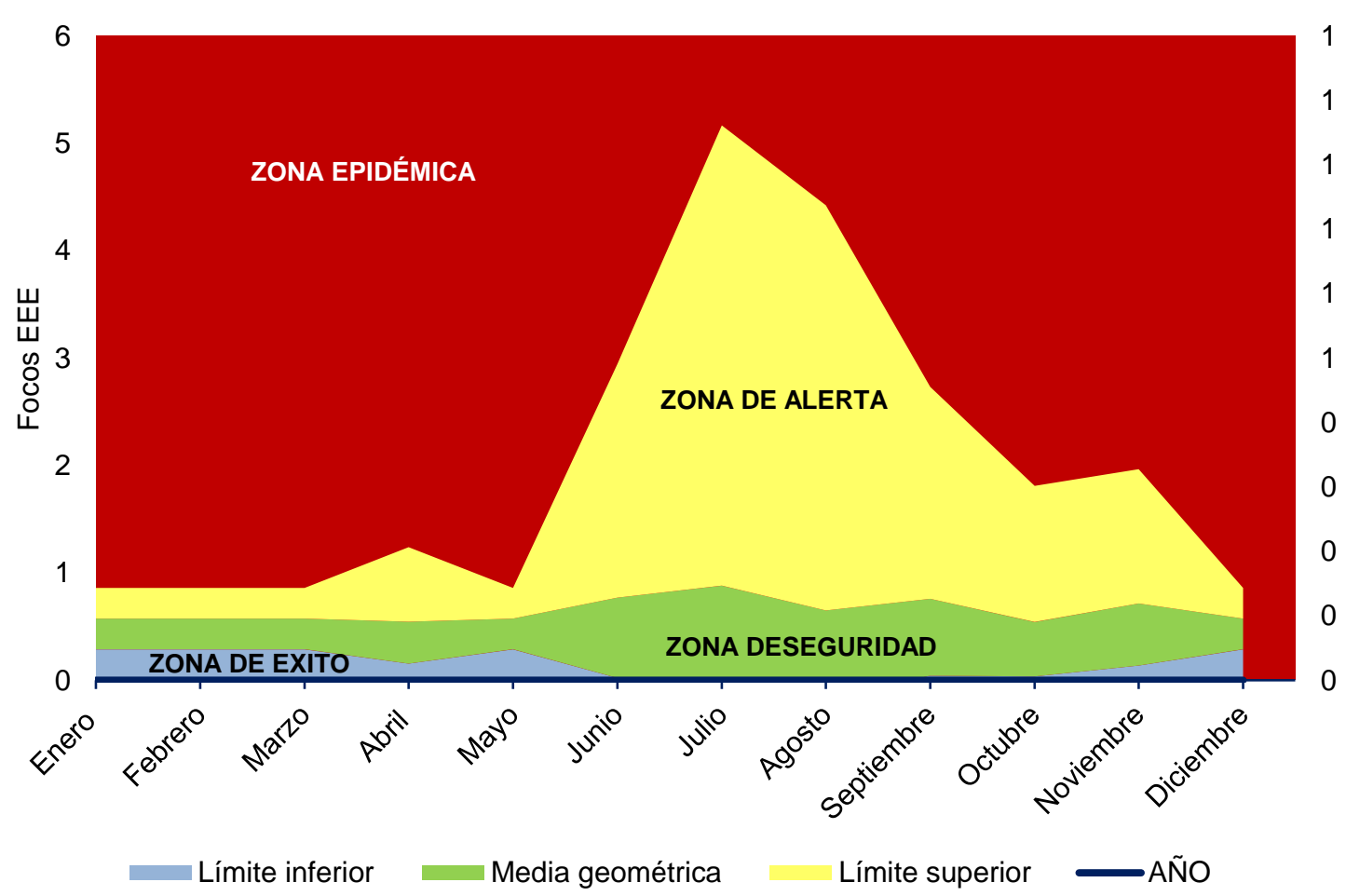

De Encefalitis Equina del Este en el departamento del Meta se presentaron ocho (8) focos en el período de estudio. En los años 2012 y 2013 no se presentaron focos. La mayor frecuencia de focos se presentó en los años 2014, 2016 y 2017, con dos (2) focos, respectivamente. Entre los años 2012 a 2018, no se presenta reporte de focos en los meses de enero y febrero; mientras que, los meses de mayor 
presentación de focos fueron marzo, abril y junio con dos (2) focos cada uno, seguido de los meses de agosto y noviembre con un (1) foco cada uno.

Según los boletines mensuales del ICA, en el año 2014, los focos de EEE se presentaron en los municipios de Puerto Gaitán en el mes de marzo y en Villavicencio en el mes de agosto; ambos municipios pertenecientes a la subregión Río Meta. En Puerto Gaitán se reportaron 24 equinos positivos, de los cuales dos (2) fallecieron; mientras que en Villavicencio se vieron afectados tres (3) equinos, con el deceso de uno de ellos.

Para el 2015, se reportó un foco en el mes de junio, en el municipio de Villavicencio, con un (1) equino positivo, el cual falleció. En el año 2016, se presentaron dos (2) focos en el municipio de Cumaral perteneciente a la subregión Capital Cordillera, uno en el mes de junio y el segundo en el mes de septiembre, con un total de 36 equinos afectados, de los cuales falleció uno solo.

Dos (2) focos de EEE se reportaron en el departamento del Meta en el año 2017, los cuales se presentaron en los municipios de Puerto Lleras y Puerto Rico, ubicados en cercanía geográfica, Puerto Lleras perteneciente a la subregión del Ariari y Puerto Rico perteneciente a la subregión del Bajo Ariari Sur. El primer foco se reportó en Puerto Lleras en el mes de marzo, seguido del foco de Puerto Rico en el mes de abril, con un foco en cada uno de ellos, respectivamente. En Puerto Lleras se reportaron 20 equinos positivos a EEE, de los cuales uno (1) falleció.

Para el año 2018 se presentó un foco en el municipio de Puerto Rico en el mes de abril, con un total de cuatro (4) equinos afectados de los cuales falleció uno de los animales. En la imagen 2, se puede observar la ubicación de los focos de EEE presentados durante el período de 2012 a 2018.

Los valores obtenidos por método de Bortman para EEE en el Meta durante los años 2012-2018 fueron de un límite superior de un foco para los meses de marzo, abril, junio y agosto. Para el año 2019 estos focos aumentaron y se reportaron los 
siguientes focos, febrero presento seis, marzo ocho, abril uno, y el resto de meses no presentaron focos.

El corredor endémico de la EEE en el departamento del Meta tuvo un trazo irregular iniciando en el mes de marzo, con estabilización hacia el mes de abril y un leve descenso hasta el mes de mayo, con un aumento pronunciado del mes de junio a julio y un repunte escalonado desde el mes de agosto, sosteniéndose linealmente al mes de diciembre. En el año control (2019) se presentó un brote epidémico de EEE en el departamento del Meta, durante los meses de febrero, marzo y abril con tres (3) focos reportados en el municipio de Puerto Rico, con un total de 15 animales afectados (Gráfica 2).

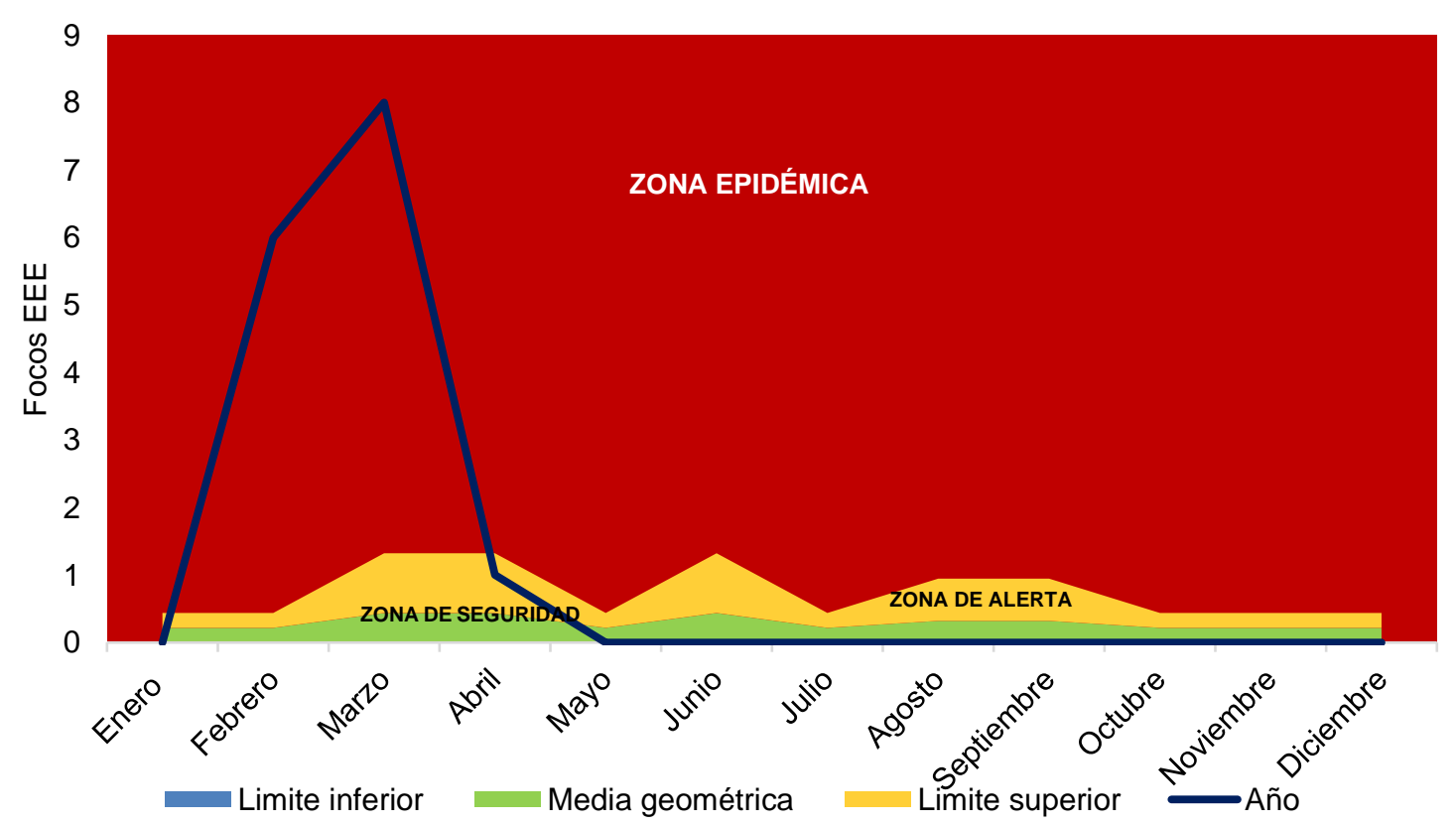

Gráfica 2. Canal endémico de EEE, Meta 2012-2018

De acuerdo, a lo mencionado por el Instituto Colombiano Agropecuario - ICA (2020), por ser la Encefalitis Equina del Este, una enfermedad que actualmente no cuenta con una vacuna autorizada en el país y considerablemente difícil ejercer acciones de control, teniendo en cuenta que la vacunación es la estrategia más eficaz para el control de encefalitis en équidos. Se hace necesario, evaluar la posibilidad de 
introducir la vacuna contra EEE para controlar los brotes en zonas endémicas (ICA, 2020).

De Encefalitis Equina Venezolana se presentaron en Casanare dos (2) focos entre los años 2012-2018, el primero en el mes de febrero del 2012, en la subregión Norte del departamento, en el municipio de Paz de Ariporo. Y el segundo en el año 2014, en el mes de abril, en el municipio de San Luis de Palenque, ubicado en la misma subregión.

Los valores obtenidos por método de Bortman para EEE en el Casanare durante los años 2012-2018 fueron de un límite superior de un foco para los meses de febrero y abril. Para el año 2019 no se presentaron focos.

El corredor endémico de la EEV en el Casanare tuvo fluctuaciones a partir del mes de febrero con un declive hacía el mes de marzo, luego un ligero aumento en el mes de abril seguido de un descenso al mes de mayo y se estabilizó hasta el mes de diciembre. El año 2019 (Control) estuvo dentro de la zona de éxito, al no presentarse focos de EEV en Casanare (Gráfica 3).

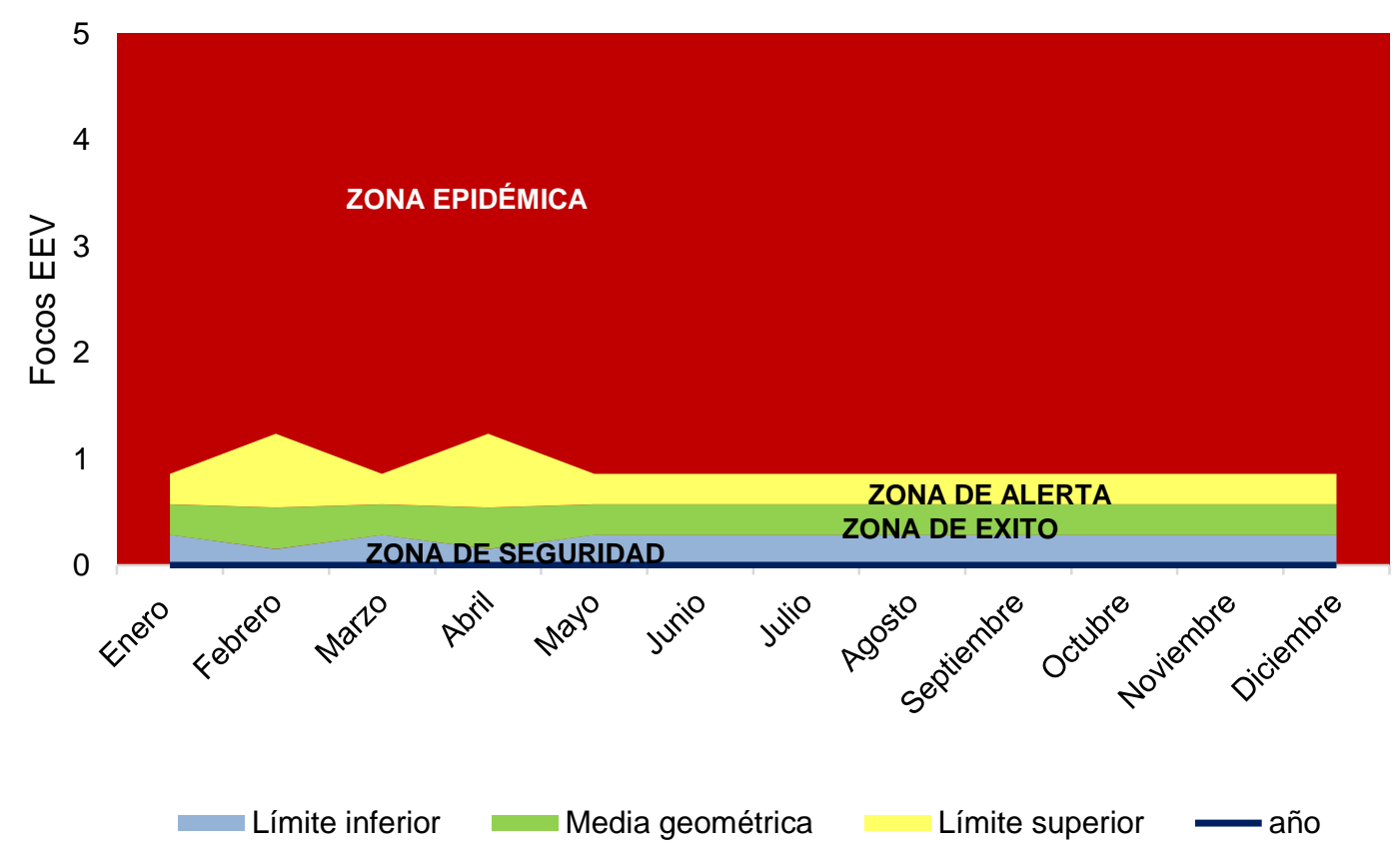


Gráfica 3. Canal endémico de EEV, Casanare, 2012-2018

Entre los años 2012 y 2018 en el departamento del Meta se presentaron dos (2) focos de EEV, reportados en el año 2016, presentándose el primer foco en el mes de enero en el municipio de Puerto Rico con 15 equinos afectados, sin decesos y el segundo en Villavicencio en el mes de julio con cinco (5) animales positivos, sin fallecidos.

Con la presentación de focos reportados por el ICA en el departamento del Meta no fue suficiente para realizar el canal endémico de la EEV, por lo que la información de los focos se tomó como datos acumulados. La base de datos incluía información del departamento de Arauca que se analizó en conjunto a los departamentos de estudio, dada la cercanía geográfica con estos y por ser de frontera. Entre los años 2012 a 2018, se presentaron en el departamento de Arauca dos (2) focos de Encefalitis Equina del Este, reportados en el año 2017, el primer foco en el mes de enero, en el municipio de Arauca, con 42 equinos afectados, de los cuales dos (2) fallecieron y el segundo foco en el mes de febrero en el municipio de Fortul. De Encefalitis Equina Venezolana no se presentaron focos o no fue reportado por parte del ICA, al faltar información de varias semanas. Sin embargo, al ser Arauca, zona de frontera, los programas de control, vigilancia y de vacunación son más rigurosos en los procedimientos de inspección sanitaria de los animales que ingresan al país, con medidas como cuarentena obligatoria, toma de muestras y envío al laboratorio para análisis y posterior vacunación de los animales.

Con la información se realizó un acumulado de 72 focos de EEE en los dos departamentos. Observándose que la mayor presentación de focos fue en el departamento del Casanare con 62 focos, seguido del departamento del Meta con ocho (8) focos y en el departamento de Arauca solo dos (2) focos. La mayor presentación de focos fue en los meses de julio con 22 focos, seguido de agosto con 21 , junio con nueve (9), septiembre con siete (7), abril, octubre y noviembre con tres (3) focos cada uno, marzo con dos (2) y enero y febrero con un (1) foco respectivamente; en los meses de mayo y diciembre no se presentaron focos en los 
departamentos de estudio. En Casanare y Meta no hubo focos en los meses de enero y febrero (Gráfica 4).

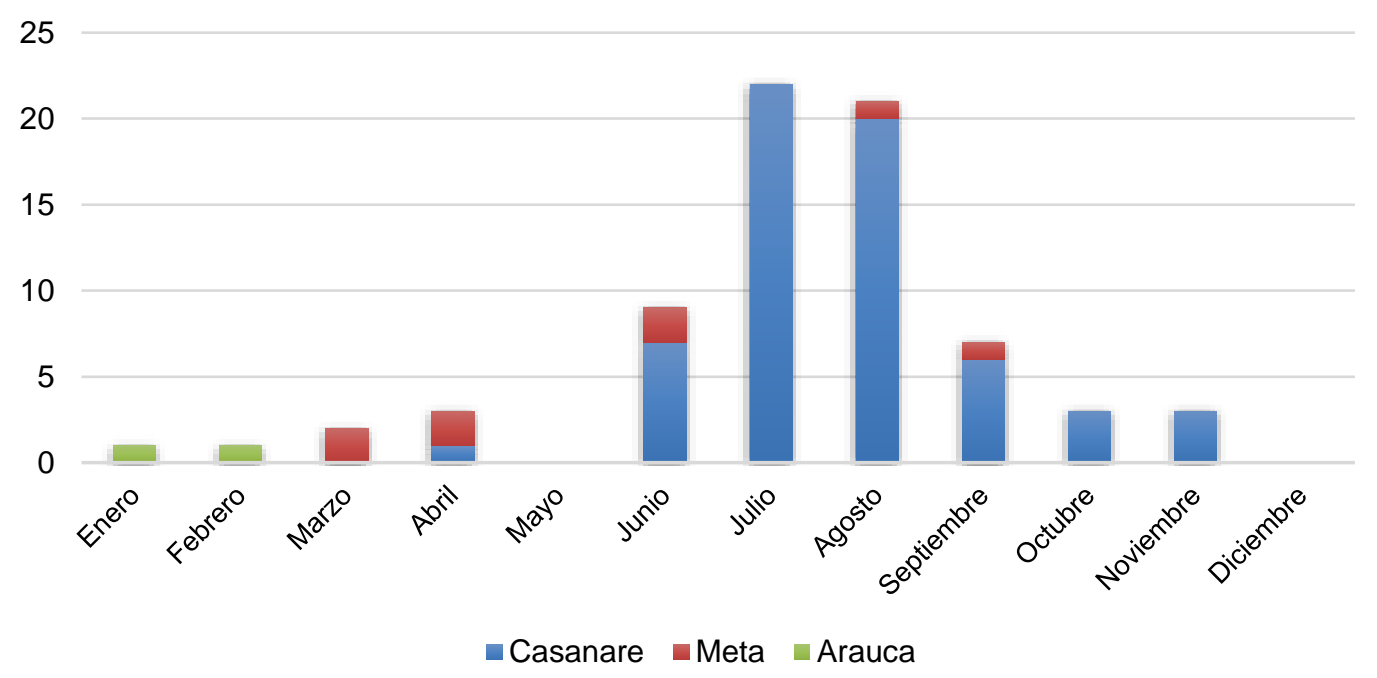

Gráfica 4. Acumulado de EEE en Casanare, Meta, Arauca 2012-2018

Entre los años 2012 a 2018, se presentó un acumulado de cuatro (4) focos de Encefalitis Equina Venezolana en los departamentos de Casanare y Meta, con dos (2) focos en cada uno ellos. Los meses en los que se presentaron los focos fueron enero, febrero, abril y julio, sin repetición en ninguno de los meses (Gráfica 5).

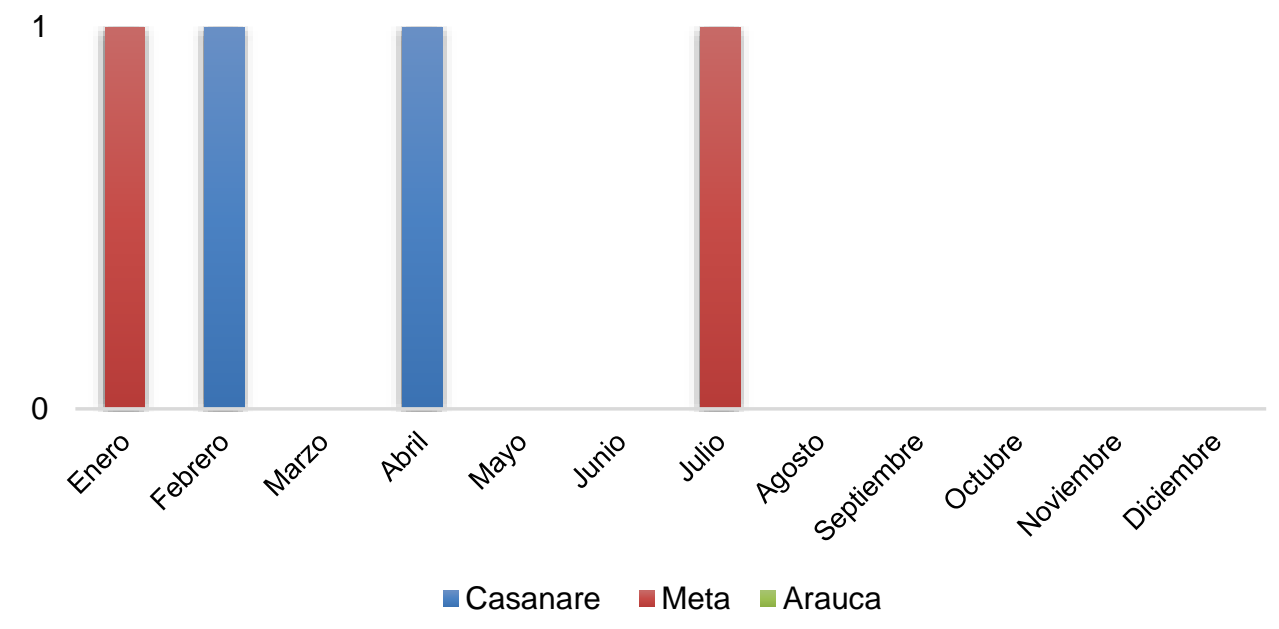

Gráfica 5. Acumulado de EEV en Casanare, Meta, Arauca 2012-2018 
Los últimos focos de Encefalitis Equina Venezolana en los departamentos del Casanare y Meta se reportaron en los años 2014 y 2016, respectivamente. Esto podría ser explicado por la rigurosidad del programa de prevención y control que viene desarrollando el ICA desde 1.999. Lo cual es ratificado en el informe de gestión del 2019, con el cual el ICA informó que fueron vacunados 161.224 équidos en el territorio nacional en zonas de riesgo de presentación de la enfermedad y que vigilaron 465 concentraciones de équidos con una población susceptible de 34.303 animales. Esto, teniendo en cuenta que la EEV es una enfermedad zoonótica y que, al vacunar a los équidos, por ser amplificadores del virus en las fases de viremia, con su control se logra impactar positivamente la salud pública de las comunidades humanas de riesgo, que conviven en las zonas por debajo de los 1.500 m.s.n.m (ICA, 2019).

La Encefalitis Equina del Este en el departamento del Casanare tuvo un comportamiento epidemiológico que superó el histórico de los años 2012 a 2015, pasando de un foco en el 2015 a 57 focos en el 2016, los cuales se presentaron en ocho (8) municipios aledaños, caracterizados por ser sabanas inundables, con áreas boscosas húmedas y pantanos o reservorios semi-permanentes de agua, estos propiciarían ambientes adecuados para los ciclos de vida de los mosquitos vectores, así como los hábitat ecológicos para la llegada de las aves migratorias. Concordando con autores como Mesa et al. (2005), CFSPH (2008) y Ferro et al. (2015), quienes explican que, en el ciclo epizoótico de la EEE, de inicio y terminación súbita de pocos meses, participan aves silvestres y migratorias, además de otros reservorios silvestres, de las que se alimentan más de 25 especies de mosquitos de los géneros Aedes y Psorophora, principalmente Aedes taeniorhynchus y Psorophora confinnis, que son los responsables de la transmisión de la enfermedad.

El Ministerio de Salud y Protección Social no reportó en Colombia, casos de Encefalitis Equina en humanos en los departamentos del Meta y Casanare en el 
período de estudio, de 2012 a 2018. Esto explicado porque solo hasta febrero de 2016 se publicó oficialmente en la página web del Instituto Nacional de Salud, el Protocolo de Vigilancia de las Encefalitis Equinas en el país y se dio inicio al reporte del evento por parte de las Entidades Territoriales de Salud (MSPS, 2016).

Adicionalmente Carrera et al. (2010), encontraron en Panamá en un estudio serológico del virus de EEE en equinos, prevalencias fuera del área principal del brote, argumentando su relación con aves migratorias, que son huéspedes amplificadores al llegar a los humedales, donde también habitan pequeños roedores silvestres que sirven de hospederos. Coincidiendo con éste estudio que los primeros focos se presentaron con el inicio de la temporada de lluvias.

Concordando con lo expuesto por ICA (2017) en el Boletín "Colombia: Sanidad 2014", que la lluvia es un factor ambiental determinante en la multiplicación de la población de mosquitos, porque incrementa las posibilidades de infectarse con el virus y de transmitirlo a las especies susceptibles durante la época de sequía, ocasionando brotes esporádicos, por lo que se evalúan los informes climatológicos del Instituto de Hidrología, Meteorología y Estudios Ambientales (IDEAM) en los años de estudio.

El boletín climatológico del año 2014 reportó que las temperaturas mínimas estuvieron por encima de la media histórica prácticamente en todo el país, pero que, en departamentos como Casanare y Meta, hubo aumento de temperatura de al menos 2 a $3^{\circ} \mathrm{C}$ en comparación con el promedio nacional. El régimen de lluvias de principio de año (diciembre a febrero) en la región Orinoquia, tuvo un déficit ligero.

Durante el período entre noviembre del 2013 a noviembre del 2014, sobre el norte de la región Orinoquia, persistieron condiciones entre ligera y moderadamente secas en los acumulados de lluvia (IDEAM, 2015). Esto contribuiría a explicar la presentación de los focos de EEE en los departamentos de Meta, Casanare entre los meses de marzo a agosto, como resultado del efecto del régimen de lluvias en 
el ciclo de vida y el número de vectores transmisores de la enfermedad; concordando con Mesa et al. (2005) que los brotes epizoóticos de encefalitis equinas están influenciados por aspectos ecológicos, demográficos y sociales.

Adicionalmente el ICA reportó que para el año 2014, se movilizaron un total de 391.003 animales en el país. El 20,6\% tuvo como finalidad feria, el 28,6\% planta de beneficio y el $50,8 \%$ predio; de los cuales en el departamento del Meta se movilizaron 28.475 equinos. Con una distribución de equinos en el departamento de Arauca de 53.500, Casanare con 113.290 y Meta con 69.920 (ICA, 2017).

EI IDEAM en el boletín climatológico del 2015, reportó lluvias entre los meses de junio y agosto con valores entre ligera y moderadamente por encima de los promedios climatológicos. El ICA reportó un censo equino en Arauca de 53.500, Casanare con 113.290 y Meta con 69.920 animales.

El boletín climatológico del IDEAM para el año 2016, informó que a partir de abril y durante el resto del año, las lluvias se reactivaron y retomaron su condición normal e incluso con excesos sobre las regiones Orinoquia y Amazonia. A partir de octubre hasta diciembre, las lluvias tuvieron tendencia hacia la condición húmeda y muy húmeda prácticamente en todo el país (IDEAM 2016). Lo cual podría contribuir a explicar la presentación de 57 de los 62 focos de EEE que se presentaron en Casanare y dos (2) de los ocho (8) focos del Meta. Según el censo pecuario del ICA para el año 2016, el inventario equino en Arauca fue de 55.402, Casanare con 99.208 y Meta con 52.090 equinos. En el departamento del Casanare en los 57 focos de EEE, se vieron afectados 871 equinos, representando el $0,87 \%$ de animales del departamento.

En el año 2017, la temporada de lluvias inició en el mes de abril en la región Caribe y Orinoquia, con mayor registro de precipitación en el piedemonte llanero (IDEAM. 2017). En el censo del ICA, en Arauca se reportan 58.170 animales, en Casanare 90.049 y en Meta 77.415. Se presentaron dos (2) focos de EEE en el departamento 
del Meta para un total de 20 infectados, representando el 0,02\% de los equinos. En el departamento de Arauca se presentaron dos (2) focos para un total de 42 equinos afectados, representando esto el $0,07 \%$ de la población.

En el boletín climatológico del año 2018, durante el mes de abril las precipitaciones estuvieron asociadas a la zona de convergencia del Atlántico Sur y el ingreso de masas húmedas procedentes del sur del continente, las cuales favorecieron las precipitaciones en la Amazonia y la transición de la época de menos lluvias, a la temporada de las precipitaciones en la región de la Orinoquia, especialmente en el piedemonte llanero del Meta (IDEAM-2018). Según el censo ICA se reportan un total de 219.517 animales distribuidos en Arauca con 52.053, Casanare con 90.049 y Meta con 77.415 équidos. En 2018 hubo dos (2) focos de EEE en el Meta y Casanare, cada uno con un foco respectivamente; para el Meta con un total de cuatro (4) animales afectados, con un promedio de 0,005\% de la población equina y para el segundo, cuatro (4) animales positivos para un promedio de $0,004 \%$.

El brote epidémico de Encefalitis Equina del Este presentado en el departamento del Meta en los meses de febrero, marzo y abril del año 2019, podría ser explicado mediante el informe climatológico mensual del IDEAM, donde se reportó que, en el mes de febrero sobre el piedemonte llanero y sectores de Casanare y Meta, la temperatura media superó el umbral de $1,0^{\circ} \mathrm{C}$ a $2,0^{\circ} \mathrm{C}$ sobre el promedio típico del mes (IDEAM, 2019), que aunado a un bajo régimen de lluvias, podría haber propiciado condiciones que acelerarán el ciclo de vida de los mosquitos, aumentando la población de los vectores transmisores de la EEE al alimentarse de sangre de los equinos. Según el censo pecuario del ICA, en el departamento del Meta se contaba con una población de 79.790 equinos.

El ICA mediante resolución 1026 de 1999, estableció las medidas sanitarias para la prevención y control de la EEV, mediante la vigilancia en eventos, movilización de equinos de un predio a otro y concentración de animales que sean por debajo de 1200 m.s.n.m. o en áreas susceptibles a presentación de la enfermedad, con la 
vacunación obligatoria, con una validez de dos (2) años. Esta vacunación deberá realizarse con 15 o más días de anterioridad a la celebración del evento. La vacunación será registrada mediante un certificado donde se registran las poblaciones de caballares, mulares y asnales menores y mayores de un (1) año y servirá de soporte para la movilización de los animales (ICA, 1999).

Para EEE no hay vacuna ni tratamiento antiviral específico, las medidas de atención primaria incluyen reposo absoluto, hidratación adecuada y terapia sintomática. El constante monitoreo del comportamiento de la enfermedad en función del tiempo y con la experiencia de lo observado en años anteriores, permite identificar los cambios que ocurren y dan la oportunidad de establecer medidas que permitan su control.

\section{CONCLUSIONES}

En el estudio, los corredores endémicos fueron una herramienta apropiada para establecer el comportamiento epidemiológico de la Encefalitis Equina Venezolana y la Encefalitis Equina del Este en los departamentos del Meta y Casanare; permitiendo identificar que en el período comprendido entre los meses de febrero a abril del año 2019, se presentó un brote epidémico de Encefalitis Equina del Este en el departamento del Meta; este conocimiento permitirá vigilar a futuro una posible reemergencia de esta enfermedad en la zona, al reunir las condiciones climáticas ideales para la perpetuación de los vectores y la migración de aves silvestres, además, que la prevención de esta patología por parte de las Instituciones oficiales de control sanitario resulta bastante difícil por la ausencia de una vacuna aprobada en el país.

Las gráficas de los corredores endémicos permitió una fácil interpretación del histórico de los focos presentados en los departamentos de estudio en el período comprendido entre 2012 a 2018, lo que contribuye a difundir y dar a conocer el comportamiento de las Encefalitis Equinas en los principales departamentos de la Orinoquia Colombiana; información que aunada a la base de datos del ICA de la 
movilidad equina, podría generar estrategias de vigilancia y control para la encefalitis equina del este.

Producto del programa de vacunación del ICA, se evidenció una baja incidencia de Encefalitis Equina Venezolana en los departamentos de estudio, con tan solo cuatro (4) focos entre los años 2012 a 2018, cada uno de éstos con dos (2) focos respectivamente.

EI ICA, debería establecer programas rigurosos de vigilancia en el departamento del Casanare por ser este, el de mayor incidencia de Encefalitis Equina del Este en el período de estudio, mediante estrategias de control en la movilidad de los equinos y pruebas de laboratorio que identifiquen animales portadores y reservorios de la enfermedad. Para esto es importante socializar los resultados de estudios y análisis en la zona con productores y propietarios de los animales, con el propósito de que participen de forma activa en el diagnostico precoz de la Encefalitis Equina del Este.

En el desarrollo del trabajo se evidenció la carencia de registros sistemáticos, con vacíos de información en tiempo y espacio, lo que resultó complejo para estudiar las tendencias de incidencia de las enfermedades, tal como sucedió con el departamento de Arauca, en el que no se logra desarrollar el canal endémico.

Sería de gran importancia la realización de proyectos encaminados a una mayor investigación de la influencia de las enfermedades de reporte obligatorio en el país, que conlleve a un diagnóstico y una prevención acertada y oportuna, contando con la participación de las entidades de salud y el sector educativo.

\section{BIBLIOGRAFÍA}

1. Acha P., Szyfres B. 2003. Zoonosis and communicable diseases common to man and animals. $3^{\mathrm{a}}$ ed. Washington DC: Pan American Health Organization.

2. Azar S., Campos R., Bergren N., Camargos V., Rossi S. 2020. Epidemic Alphaviruses: Ecology, Emergence and Outbreaks. Microorganisms. Aug 1; 8(8): 1167.

3. Bortman M. 1999. Elaboración de corredores o canales endémicos mediante planillas de cálculo. Revista Panamericana de Salud Publica. 5 (1). 03-12-2020 En: https://www.scielosp.org/pdf/rpsp/1999.v5n1/1-8/es 
4. Carrera J., Bagamian K., Travassos da Rosa A., Wang E., Beltran D., Gundaker N., Armien B., Arroyo G., Sosa N., Pascale M., Valderrama A., Tesh R., Vittor A., Weaver S. 2018. Human and Equine Infection with Alphaviruses and Flaviviruses in Panamá during 2010: A Cross-Sectional Study of Household Contacts during an Encephalitis Outbreak. The American Journal of Tropical Medicine and Hygiene. Volume 98, Issue 6

5. CFSPH. 2008. Center for Food Security and Public Health. Encefalomielitis equina: del este, del oeste y venezolana. Recuperado: 16-11-2020. En: http://www.cfsph.iastate.edu/Factsheets/es/equine encephalitides-es.pdf

6. Ferro C., De las Salas J., González M., Díaz A., Cabrera C., Flórez Z., Duque M., Lugo L., Bello B. 2015. ¿Existen condiciones que favorecen la reaparición del virus de la encefalitis equina venezolana en la Alta Guajira colombiana? Biomédica; 35:62-72.

7. Forrester N., Wertheim J., Dugan V., Auguste A., Lin D., Adams A., Chen R., Gorchakov R., Leal G., Estrada-Franco J., Pandya J., Halpin R., Hari K., Jain R., Stockwell T., Das S., Wentworth D., Smith M., Kosakovsky P., Weaver S. 2017. Evolution and spread of Venezuelan equine encephalitis complex alphavirus in the Americas. PLoS Neglected Tropical Diseases. Aug 3;11(8).

8. Guzmán C., Calderón A., Rodríguez A., Mattar S. 2020. Venezuelan equine encephalitis virus: the problem is not over for tropical America. Ann Clinical Microbiology Antimicrobial. May 19; 19(1):19.

9. ICA. 2008. Instituto Colombiano Agropecuario. Colombia, Sanidad Animal. Recuperado: 21-10-2020. En: https://www.ica.gov.co/getattachment/e205da92-1991-4de4-b41229d6dae2ae40/2008-(1).aspx

10. ICA. 2009. Colombia, Sanidad Animal. Recuperado: 21-10-2020. En: https://www.ica.gov.co/getattachment/7b0e7f6a-4c43-4dff-be39ab9f4d1b0e0a/2009.aspx

11. ICA. 2013. ICA comunica. Encefalitis equina venezolana. En: https://www.ica.gov.co/periodico-virtual/prensa/informe-especial-encefalitisequina-venezolana

12. ICA. 2017. Colombia: Sanidad Animal 2014. 25-04-2021. En: https://www.ica.gov.co/getattachment/986dd783-8f37-4ab3-bc3339995bd8c065/2014.aspx

13. ICA. 2019. Informe de Gestión 2019. En: 15-05-2021. En: https://www.ica.gov.co/getattachment/Modelo-de-P-y-G/TransparenciaParticipacion-y-Servicio-al-Ciudada/Rendicion-de-Cuentas/Informe-deGestion-ICA-2019.pdf.aspx?lang=es-CO

14. ICA. 2020a. Encefalitis equina. En: https://www.ica.gov.co/getdoc/0408af847210-4d0d-ba47-74aa903cbf48/encefalitis-equina-(1).aspx

15. ICA. 2020b. Informe memorias del Congreso de la República 2019 - 2020 acciones desarrolladas por el ICA. Productividad + rentabilidad $=$ competitividad. En: https://www.ica.gov.co/getattachment/Modelo-de-P-yG/Transparencia-Participacion-y-Servicio-al-Ciudada/POLITICA-DE-

RIESGOS/Informes-ICA-Memorias-del-Congreso-20192020.pdf.aspx?lang=es-CO 
16. IDEAM 2014.Boletin Climatológico de Colombia En: http://www.ideam.gov.co/web/tiempo-y-clima/climatologicomensual? $p \mathrm{p} i \mathrm{~d}=110$ INSTANCE $x Y v \mid$ IPc4uxk1Y\&p $p$ lifecycle $=0 \& p p$ stat e=normal\&p $p$ mode $=v i e w \& p$ col id=column-

17. IDEAM. 2015. Boletín Climatológico de Colombia. En: http://www.ideam.gov.co/documents/21021/299805/Anuario Climatol\%C3\%B 3gico 2014.pdf/89f8d50c-fbeb-4769-8241-be774cb3252e?version=1.0

18. IDEAM 2016 Boletín Climatológico de Colombia En: http://www.ideam.gov.co/web/tiempo-y-clima/climatologicomensual? $p \mathrm{p} i \mathrm{~d}=110$ INSTANCE $x$ YvIPc4uxk1Y\&p $p$ lifecycle $=0 \& p p$ stat $\mathrm{e}=$ normal\&p $\mathrm{p}$ mode $=$ view\& $\mathrm{p}$ col id=column-

19. IDEAM 2017 Boletín Climatológico de Colombia. En: http://www.ideam.gov.co/web/tiempo-y-clima/climatologicomensual? $p \mathrm{p} i \mathrm{~d}=110$ INSTANCE $x Y v \mid$ IPc4uxk1Y\&p $p$ lifecycle=0\&p $p$ stat $\mathrm{e}=$ normal\&p $\mathrm{p}$ mode $=$ view\&p $\mathrm{p}$ col $i \mathrm{~d}=$ column-

20. IDEAM 2018 Boletín climatológico de Colombia En: http://www.ideam.gov.co/web/tiempo-y-clima/climatologicomensual? $p$ p id=110 INSTANCE xYvIPc4uxk1Y\&p $p$ lifecycle=0\&p $p$ stat $\mathrm{e}=$ normal\&p $\mathrm{p}$ mode $=$ view\& $\mathrm{p}$ col id=column-

21. IDEAM 2019 Boletín Climatológico de Colombia En: http://www.ideam.gov.co/web/tiempo-y-clima/climatologicomensual? $p \mathrm{p} i \mathrm{~d}=110$ INSTANCE $x$ YvlPc4uxk1Y\&p $p$ lifecycle $=0 \& p p$ stat $\mathrm{e}=$ normal\&p $\mathrm{p}$ mode $=$ view\& $\mathrm{p}$ col id=column-

22. INS. 2017. Instituto Nacional de Salud. Protocolo de vigilancia en salud pública. Encefalitis Equina. Recuperado: 16-11-2020. En: https://www.ins.gov.co/buscadoreventos/Lineamientos/Encefalitis\%20Equinas\%20PROTOCOLO .pdf

23. Kumar B., Manuja A., Gulati B., Virmani N., Tripathi B. 2018. Zoonotic Viral Diseases of Equines and Their Impact on Human and Animal Health. Open Virology Journal. Aug 31; 12: 80-98.

24. Mattar S., Arrieta G., Álvarez J. 2008. Virus del Oeste del Nilo en el Caribe colombiano. Infectio; 12(1):25 a 27.

25. Mesa F., Cárdenas J., Villamil L. 2005. Las Encefalitis equinas en la Salud Pública. $1^{a}$ ed. Bogotá Colombia: Universidad Nacional de Colombia.

26. MS. 1995. Ministerio de Salud. Encefalitis Equina Venezolana en la Guajira: Informe quincenal de casos y brotes de enfermedades. Bogotá: 5; 1(3):9-15.

27. MS. 1999. Ministerio de Salud. Manual de Enfermedades Zoonóticas. Santa Fé de Bogotá D.C; Colombia. Pag: $7-18$.

28. MSPS. 2016. Ministerio de Salud y Protección Social. Documento de análisis de la situación en salud ambiental del componente de zoonosis desarrollo intersectorial de las fases de gestión de información. En: 20-05-2021. En: https://www.minsalud.gov.co/sites/rid/Lists/BibliotecaDigital/RIDE/VS/PP/SA/a nalisis-situacion-salud-ambiental-zoonosis.pdf

29. OPS. 2011. Organización Panamericana de la Salud. Encefalitis Equinas Transmitidas por artrópodos. Recuperado 16-11-2020. En: https://www.paho.org/panaftosa/index.php?option=com docman\&view=downl 
oad\&category slug=zoonosis-779\&alias=57-encefalitis-equinas-transmitidaspor-artropodos- $7 \&$ ltemid $=518$ 